\title{
La ley defensa de la democracia: derecho e historia en los debates parlamentarios de la transición (1983-1984)
}

\section{Democracy defence act: law and history in the parliamentary debates of the transition (1983-1984)}

\author{
Velázquez Ramírez, Adrián
}

\section{Adrián Velázquez Ramírez}

adrian.velaram@gmail.com

Universidad Nacional de San Martín, Argentina

Estudios Sociales. Revista Universitaria Semestral Universidad Nacional del Litoral, Argentina

ISSN: 0327-4934

ISSN-e: 2250-6950

Periodicidad: Semestral

núm. 61, e0007, 2021

estudiossociales@unl.edu.ar

Recepción: 21 Agosto 2019

Aprobación: 24 Junio 2020

URL: http://portal.amelica.org/ameli/jatsRepo/293/2932743009/ index.html

DOI: https://doi.org/10.14409/es.2021.2.e0007

El contenido está bajo Licencia Creative Commons AtribuciónNoComercial-Compartir Igual 4.0 Internacional. Atribución - No Comercial - Compartir Igual (BY-NC-SA): no se permite un uso comercial de la obra original ni de las posibles obras derivadas, la distribución de las cuales se debe hacer con una licencia igual a la que regula la obra original.

\section{(i) (2)}

Esta obra está bajo una Licencia Creative Commons AtribuciónCompartirIgual 4.0 Internacional.
Resumen: El artículo analiza los debates parlamentarios sobre la Ley de Protección del Orden Constitucional y la Vida Democrática (Ley 23077), aprobada el 9 de agosto de 1984 durante el gobierno de Raúl Alfonsín (1983-1989). El objetivo es indagar en los sentidos y representaciones que sirvieron de marco justificatorio, así como en la retórica jurídica que se empleó para convertir a la democracia en un bien jurídico protegido. De esta manera, el artículo busca ofrecer una mirada a los cambios en el discurso jurídico durante la transición a la democracia. Partiendo de lo que hemos llamado como una «fenomenología del legislador», resulta particularmente relevante cómo se establece en los debates parlamentarios la relación entre la ley propuesta y la experiencia histórica.

Palabras clave: transición a la democracia, Argentina, Ley de Defensa de la Democracia, derecho, historia conceptual.

Abstract: The article discusses parliamentary debates on the «law on the protection of constitutional order and democratic life» (Law 23077), adopted on 9 August 1984 during the government of Raúl Alfonsín (1983-1989). The aim is to investigate the senses and representations that served as a justification framework, as well as in the legal rhetoric used to turn democracy into a protected legal good. In this way, the article seeks to offer a glimpse into the changes in legal discourse during the transition to democracy. On the basis of what we have called as a 'legislator's phenomenology', it is particularly relevant how the relationship between the proposed law and historical experience is established in parliamentary debates.

Keywords: transition to democracy, Argentina, democracy defence act, law, conceptual history.

\section{Introducción: lo político en el camino de Möbius}

En La cuadratura del circulo: la Constitución argentina como testimonio de la imposible normativización de lo politico, Jorge Dotti realiza un brillante análisis 
de las figuras que en la Carta Magna abordan el problema de la autodefensa del orden jurídico. Situado desde un marco schmittiano, el objetivo de su recorrido es identificar cómo aparece en dicho cuerpo normativo la paradoja de «tener que regular lo irregulable», es decir, de establecer aquellas «conductas excepcionales de la autoridad en el estado de excepción para la protección del orden estatal» (Dotti, 2011: 169). En estas figuras la soberanía se reserva un alto grado de discrecionalidad que en condiciones de crisis severa o amenaza externa resulta necesaria para mantener a resguardo al Estado y su ordenamiento jurídico. En otras palabras, en estas figuras anida «el impulso a retrotraer el orden al estadio donde es necesaria la decisión soberana originaria». De esta manera podemos encontrar en la propia Constitución las huellas de la bestia indómita de lo político ${ }^{[1] .}$

Con este objetivo, el artículo de Dotti ofrece un repaso a través de figuras como el estado de sitio, los decretos de necesidad y urgencia y el delito de sedición. En términos generales, estas cláusulas se mueven dentro de un axioma general: tanto más efectiva resulta una figura para resguardar el orden estatal, más esta se aleja de la fuerza normativa de la Constitución. Es decir, hay una relación directa entre la efectividad de estos recursos y el margen de maniobra que obtiene aquel que decide en última instancia sobre la excepcionalidad. Sin embargo, en el análisis de la última figura que analiza Dotti este axioma general se ve impugnado. Se trata del artículo 36 constitucional, primero de la nueva sección de derechos y garantías que incorporó la Asamblea Constituyente de 1994.

En efecto, desde los supuestos iniciales de los que parte Dotti, el 36 constitucional resulta sumamente problemático. En particular, son dos los elementos que tensionan su análisis. El primero de ellos refiere a que dicho artículo establece que «la Constitución mantendrá su imperio aun cuando se interrumpiere su observancia por actos de fuerza», declarando como insanablemente nulo todo acto legislativo emanado por el gobierno de facto derivado de esta situación. El segundo es que, en su párrafo cuarto, dicho artículo otorga el derecho de resistencia «contra quienes ejecutaren los actos de fuerza enunciados en este artículo». De tal manera que, a diferencia de las otras figuras, este artículo tiene como supuesto que el orden constitucional ya ha sido vulnerado. Es decir, es una figura de excepción que se activa cuando la Constitución ya ha perdido vigencia. De ahí que, en contraste con el resto de las normas revisadas, Dotti no pueda sino poner en duda la juricidad de un derecho cuya supuesto «es la imposibilidad de respaldar jurídicamente (autorizar y proteger) a quien efectiviza tal derecho», es decir, al ciudadano que resiste. En otras palabras, esta cláusula no otorga ningún margen de maniobra pues se opone a un poder que ya se ha hecho del poder coercitivo del Estado. En todo caso afirma Dotti- «para los actores del acto de fuerza exitoso y ahora autoridades del gobierno, la resistencia justificada desde una constitución anulada es una amenaza para el nuevo régimen y reprimirla equivale a seguir adelante con la superación de la situación excepcional luego de haber tenido éxito en la toma del poder» (Dotti, 2011: 240), A partir de esa aporía, Dotti sólo puede explicar dicho artículo aduciendo a su contenido moral, puramente expresivo y reivindicativo de una ética republicana jurídicamente impotente.

Sin embargo, es necesario advertir que el artículo 36 tiene una genealogía jurídica particular. A contramano del trayecto esperado en el cual una norma 
constitucional sienta las bases de las leyes secundarias posteriores, este artículo tiene como antecedentes dos leyes aprobadas en los primeros meses del gobierno de Raúl Alfonsín (1983-1989): la derogación de la autoamnistía militar (Ley 23040) y la Ley de Protección del Orden Constitucional y la Vida Democrática (Ley 23077), también conocida como Ley de Defensa de la Democracia. Estas leyes formaron parte del primer paquete de medidas que Alfonsín envió al Congreso y denotaban una fuerte impronta refundacional ${ }^{[2]}$. Ambas tuvieron por objeto reconstruir el vínculo entre derecho y democracia, marcando un corte con la matriz de derecho revolucionario vigente hasta entonces.

En efecto, hasta 1983 la llamada doctrina de los gobiernos de facto reconocía la validez de las normas dictadas por un gobierno que se había hecho por la fuerza de la titularidad del Estado (Velázquez, 2020). La derogación de la autoamnistía militar implicó así un quiebre en la tradición jurídica argentina al declarar como insanablemente nula esta medida con la cual la última dictadura militar intentó impedir la revisión de los crímenes perpetrados durante el combate a las organizaciones armadas de izquierda. Con ello, la legitimidad de origen pasó a ser parte constitutiva de la legalidad de las leyes. Por su parte, la Ley 23077 convirtió a la democracia en un bien jurídico protegido, reformando el código penal con el objetivo de ofrecer un marco de protección diferente a aquel que caracterizó la legislación penal derivada de la doctrina de seguridad nacional.

En el presente artículo nos concentraremos en la Ley de Defensa de la Democracia, analizando bajo qué lógica se construyó ahí a la democracia como un bien jurídico protegido. Con ello intentaremos ofrecer un marco para intentar solventar el callejón sin salida al que llegó el puntilloso análisis de Dotti. Para ello indagaremos en la retórica bajo la cual fue introducido este nuevo bien jurídico y que sin duda resulta extraña al decisionismo schmittiano, pues en efecto, no se trata de un derecho que busque la protección del orden estatal, sino que, por el contrario, alude a un virtual derecho a la democracia que incluso puede llegar a oponerse al orden estatal si este ha sido conquistado por la fuerza. ¿Cuál es la naturaleza jurídica de este tipo de derecho? ¿Cómo aprehender un derecho que se vincula de forma paradójica con el orden estatal? Para aproximarnos a responder estas preguntas revisaremos los debates parlamentarios de la ley en cuestión.

Con este objetivo el artículo indaga en los cambios que la transición a la democracia introdujo en el discurso jurídico. Con la apertura política de 1983, la dimensión jurídica de la vida colectiva se convirtió en un protagonista central del debate político. La relevancia que adquirió la política de derechos humanos impulsada por el gobierno de Alfonsín ha ido en consonancia con la atención que esta ha recibido dentro de las ciencias sociales y humanas en Argentina, en particular dentro del campo de estudios de la historia reciente (Acuña, González Bombal, Jelin, Landi, Quevedo, Smulovitz y Vacchieri, 1995; González Bombal, 1995; Feld, 2002; Malamud Goti, 2000; Jelin, 2007; Crenzel, 2008; Vezzetti, 2008; Yanzón, 2011).

En contraste con el énfasis puesto en el Juicio a las Juntas en tanto acto refundacional del Estado de derecho durante la posdictadura, los debates parlamentarios que habilitaron la política de justicia transicional han recibido menor atención (Aboy Carlés, 2001; Galante, 2015). Sin embargo, desde nuestra perspectiva, los debates legislativos constituyen un interesante registro para indagar en los sentidos y representaciones vinculados a cómo se planteó la 
relación entre derecho y democracia durante este periodo. El tratamiento de la ley en cuestión ofreció un escenario que los legisladores valoraron como fundamental para recrear el vínculo representativo con la sociedad. De ahí que una de las características de su discurso es que se asuman como portavoces de un mandato inequívoco que han recibido y que intentan plasmar en leyes ${ }^{[3]}$. Es precisamente esta dimensión fenomenológica vinculada al papel que el legislador asume frente a la ley que produce la que da forma a nuestro abordaje metodológico $^{[4]}$.

Desde esta perspectiva nos preguntamos por cómo se resuelve fenomenológicamente el vínculo entre la subjetividad del legislador y el carácter objetivo de la ley. A partir del análisis realizado, trazamos tres andariveles entre los cuales podemos aproximarnos a esta cuestión. En su experiencia frente a la ley el legislador asume el derecho como: a) una intervención sobre una tendencia histórica; b) como una formalización de la experiencia histórica; y c) como una clarificación de los términos políticos. En este sentido consideramos que el papel que jugó la experiencia histórica en la retórica parlamentaria fue fundamental para construir a la democracia como un bien jurídico protegido.

\section{La frontera interna del pluralismo democrático}

Aprobada el 9 de agosto de 1984, la Ley de Protección al Orden Constitucional y la Vida Democrática (Ley 23077) tuvo un tratamiento legislativo complejo. Su sanción definitiva tuvo que esperar a que el proyecto de ley fuera tratado en dos términos en las cámaras de Diputados y Senadores. Esto se explica en buena medida porque se trataba de una reforma al Código Penal. En efecto, el proyecto que envió el Ejecutivo estaba organizado en torno a dos grandes ejes. Un primer aspecto era que derogaba la legislación represiva que sirvió de marco a la violencia política estatal precedente. Por lo que implicó una pormenorizada revisión de la legislación penal introducida tanto por el gobierno constitucional de 1973-1976 como por la dictadura militar de $1976^{[5]}$. Tarea que no siempre fue fácil pues se debió considerar los posibles vacíos jurídicos que la derogación propiciaba.

El segundo aspecto que contemplaba la Ley de Defensa de la Democracia era que introducía una serie de cambios en el propio Código Penal cuyo objetivo era hacer del «orden constitucional y la vida democrática» un bien jurídico protegido. Una vez depurado el Código Penal de la legislación represiva, el proyecto de ley del Ejecutivo buscaba establecer los medios idóneos para defender a la democracia de sus «peligros internos». Esto llevó a buscar un tratamiento que se diferenciara de los mecanismos represivos empleados en el pasado, en particular de la doctrina de Seguridad Nacional (ver: Piotti y Fernández, 1985). En este punto el esfuerzo estuvo puesto en evitar que la nueva ley funcionara como un instrumento de «persecución ideológica», cuidando de no penar el «derecho de opinión». En la perspectiva del legislador oficialista por Mendoza, Alfredo Mosso (UCR), esta cuestión le permitiría al parlamento alejarse de la «legislación totalitaria» y dotar a la recién recuperada democracia de los mecanismos legales para proteger el renovado pacto de convivencia pluralista. En la fundamentación del Ejecutivo, este contrapunto con la legislación represiva aparece planteado de la siguiente manera: 
«Las leyes a derogar constituyen casos de normas de inequívoca inspiración totalitaria, cuya amplitud y elasticidad se prestan a la persecución ideológica de disidentes y cuyas penas demoníacas — sobre todo la de muerte - están concebidas bajo el presupuesto de la aniquilación del enemigo, más que como instrumentos de prevención de hechos gravemente dañinos para la convivencia generados en el seno de una sociedad libre»[6].

En un momento en el cual el pluralismo era elevado como un valor central de la convivencia democrática, se trataba de legislar sobre los medios adecuados para mantenerlo a resguardo. Esto implicó elaborar un delicado equilibrio jurídico entre el respeto a la disidencia ideológica y la exclusión de aquellas conductas que pudieran poner en riesgo dicho marco de convivencia. De esta manera, el proyecto pivoteaba en torno al establecimiento de un límite: para que el pluralismo se realizara efectivamente, la ley debía excluir aquellas manifestaciones que no lo asumieran como principio rector de la vida pública ${ }^{[7]}$. En una de sus intervenciones, el senador Fernando de la Rúa (UCR) se preguntaba:

« ¿Se debe permanecer inerte ante el avance de métodos violentos o debe combatírselos con las armas?» a lo que contestaba que: «Ni la democracia debe ser inerte, ni la libertad debe ser un pretexto para que bajo su amparo se preparen las armas para destruirla. En una palabra, en nombre de la democracia y el pluralismo no deben agazaparse quienes no quieren y no admiten esos valores» ${ }^{[8]}$.

Quedando vedada la imposibilidad de excluir del juego democrático a cualquier actor por su sistema de creencias, la ley focalizaba en aquellos medios que se consideraba ponían en riesgo el renovado pacto pluralista (Velázquez, 2020). En este sentido la medida legislativa debe verse como parte de una amplia crítica a la violencia política que durante la transición se estableció tanto como una frontera con el pasado reciente, así como la portadora de un futuro de estabilidad política (Aboy Carlés, 2001).

¿Cuáles eran, entonces, estos peligros internos de los cuales había que proteger a la democracia? Tanto en la fundamentación del Ejecutivo como en gran parte de las intervenciones de los legisladores, la llamada «teoría de los demonios» actuó como el marco justificatorio del proyecto de ley. Son dos los tipos de experiencias que van a ser centrales para asignarle valor a la Ley de Defensa de la Democracia: por un lado, los golpes de Estado, por el otro, el terrorismo. Término, este último, con el cual se pretendió darle un encuadre distinto a la terminología de las leyes represivas ancladas en el concepto de «subversión» y en la doctrina de la seguridad nacional. En la Ley de Defensa de la Democracia, la frontera interna de la democracia se constituye en un punto equidistante entre la violencia estatal y la de las organizaciones armadas de izquierda. Se trataba, por lo tanto, de excluir el uso de la fuerza como medio legal y legítimo de la democracia. En la Cámara de Diputados, Augusto Conte ${ }^{[9]}$, legislador por la Democracia Cristiana y figura importante del movimiento de derechos y humanos, dejó en claro su discrepancia «con el hecho de que se haya pretendido reunir en un solo proyecto dos fenómenos distintos de nuestra experiencia y de nuestra realidad histórica, como son el golpismo y las asociaciones ilícitas con fines terroristas ${ }^{[10]}$.

Para el Ejecutivo, la Ley de Defensa de la Democracia subsanaba algunos defectos característicos de las leyes represivas precedentes tanto en Argentina como en la legislación comparada. En contraste con estas experiencias, el proyecto 
procuraba «no incurrir en descripciones inaceptablemente imprecisas o que se prestan a interpretaciones abusivas conducentes a la persecución ideológica» ${ }^{[11]}$. De ahí que resultara fundamental «eludir toda invocación de fines o propósitos subjetivos en la redacción de los tipos, ya que esto torna insegura y arbitraria la aplicación de las normas y presupone, en última instancia, una política antiliberal de penar a gente por rasgos disvaliosos de su carácter (reflejados en sus propósitos) y no por la peligrosidad o dañosidad objetiva de su conducta» ${ }^{[12]}$.

La diferenciación entre fines subjetivos y la objetividad de la conducta fue presentada por la mayoría de los legisladores como una innovación jurídica importante. Si se toma como referencia la ya mencionada Ley de Seguridad Nacional (20840), esta distinción se diluye en un marco que termina aludiendo a la inherente peligrosidad de las ideologías (ver: Franco, 2012 y Azzolini, 2018). En el artículo 1 de esta ley se afirma que será motivo de sanción aquellas acciones «que, para lograr la finalidad de sus postulados ideológicos, intente o preconice por cualquier medio, alterar o suprimir el orden institucional y la paz social de la Nación». Mientras que en el artículo 2 penaba la «divulgación, propaganda o difusión tendiente al adoctrinamiento, proselitismo o instrucción de las conductas previstas en el artículo $1 \gg$. De ahí que la tipificación del delito facilitara a que se estableciera un nexo causal entre filiación ideología y la potencial amenaza contra el orden y la paz social. En la Ley de Defensa de la Democracia discutida en 1984 la referencia a las ideologías desaparece, siendo la única condición de cumplimiento del delito que tipifica el que objetivamente se incurriera en una acción que amenazare o dañare el orden constitucional y la vida democrática, sin que sean relevantes las motivaciones ideológicas.

Sin embargo, el hecho de que el contrapunto con la legislación represiva anterior funcionara como un punto esencial en la fundamentación de la ley, no impidió que en el transcurso del debate parlamentario se escucharan intervenciones que reproducían algunas de las premisas asociadas a ese pasado que la Ley de Defensa de la Democracia pretendía obturar. En este sentido, el senador radical por Córdoba, Felipe Celli argumentó a favor de contar con instrumentos legales para la defensa de la democracia aludiendo al artículo 29 constitucional, afirmando que se trataba de una cláusula anti-totalitaria de gran arraigo histórico y que excluía expresamente cierto tipo de ideologías. En este sentido, recordaba fallos judiciales en los cuales la Suprema Corte «reiteradamente ha negado el derecho de reunión al comunismo, fundada en que no se puede conceder derecho de reunión a sistemas que tienen el fin de poner el honor, la vida y la fortuna de los argentinos a merced de una persona o un gobierno» ${ }^{[13]}$. Y más adelante, al referirse a las amenazas de la democracia recordaba que en la segunda mitad del siglo XX había «aparecido un régimen, una legitimidad que se opone a nuestro ideal histórico, que es la democracia. Esa legitimidad es la del régimen cubano». Así también, para el senador del Partido Liberal de Corrientes, Ricardo Laconte $^{[14]}$ era menester «afirmar la Constitución y la democracia contra la demagogia, contra la subversión marxista [y] los golpes de Estado» ${ }^{[15]}$. Desde la perspectiva de estos legisladores, la Ley de Defensa de la Democracia tenía un destinatario con nombre y apellido.

Como decíamos, una de las características del cambio de perspectiva que buscó introducir la Ley de Defensa de la Democracia tiene que ver con el tipo de 
tratamiento que daba al delito de «terrorismo». En el proyecto del Ejecutivo se afirma que la nueva ley de defensa «parte de la base de que si bien el terrorismo es uno de los más serios flagelos contemporáneos para la estabilidad de las instituciones democráticas debe ser tratado como una manifestación gravísima de delincuencia y no como una agresión a la que el Estado deba responder con los mismos métodos y en el mismo plano de beligerancia». Bajo esta concepción, se afirma que «el terrorista asume una responsabilidad muy grande por el daño que causa a la sociedad, pero no queda segregado de ella». Como veremos enseguida, en claro contraste con la doctrina de seguridad nacional, en la Ley de Defensa de la Democracia la frontera interna de la democracia pluralista se constituye de manera muy diferente

Del particular tratamiento al problema del terrorismo que propone la Ley de Defensa de la Democracia se derivan dos consecuencias importantes. En primer lugar, que la ley define a este hecho como un caso de delincuencia y no como una amenaza contra el Estado, rompiendo con ello con el tratamiento adoptado por la doctrina de seguridad nacional. Con ello se evita situarlo dentro de un posible régimen de excepcionalidad que favorecería tanto la persecución ideológica extralegal, así como una respuesta del Estado acorde a la identificación de un enemigo interno al cual hay que combatir bélicamente. Un segundo aspecto refiere a que el terrorismo es considerado no como un delito en sí mismo, sino como un agravante. De esta manera quedaba establecida «una exigencia de doble encuadramiento típico, que constituye una cortapisa importante al intento de desnaturalizar la norma con fines de persecución ideológica. No basta atacar la vigencia de la Constitución, debe hacérselo a través de un acto que constituya un delito con independencia de aquel resultado» ${ }^{[16]}$. Bajo estos preceptos, la Ley de Defensa de la Democracia incluyó en el Código Penal el artículo 227 que establece que «el máximo de la pena establecida para cualquier delito será aumentado en un medio, cuando la acción contribuya a poner en peligro la vigencia de la Constitución Nacional».

Vemos entonces que, con el cambio de paradigma que introdujo la Ley de Defensa de la Democracia, la frontera interna de la democracia se constituye a partir de las siguientes consideraciones. En primer lugar, que lo que es excluido no son perfiles ideológicos, sino aquellos medios que se consideran disvaliosos para el marco de convivencia. La dinámica democrática es presentada en directa oposición al uso de la fuerza para acceder al Estado y a la violencia como medio de participación en la comunidad política. En segundo lugar, que aquellos agentes que pudieran incurrir en estos actos no son caracterizados por la ley como un enemigo total que amenaza al Estado, sino que este daño es interpretado como un acto de delincuencia que se agrava a partir del bien jurídico que resulta perjudicado. En este punto es interesante advertir que la posibilidad de tramitar jurídicamente las amenazas al pacto de convivencia parece tener como condición necesaria una clausura de la dimensión política del problema de los «peligros internos». La condición para que estos agravios puedan ser capturados y tramitados por el derecho es restringiendo su carácter político, mismo que queda excluido de las consideraciones de la ley. Ahora bien, para fundamentar esta despolitización del problema de la amenaza interna, es necesario mostrar que el bien jurídico protegido no admite una refutación política, sino sólo criminal. Como veremos en seguida, en esta operación resulta fundamental la manera en 
cual la Ley de Defensa de la Democracia construye el bien jurídico que tutela y que se compone por el sintagma: orden constitucional y vida democrática. $\mathrm{Al}$ ser incorporado en el discurso jurídico como un bien tutelado, la democracia es presentada como un orden que no acepta ser cuestionado. En el debate legislativo la experiencia histórica fue central para justificar y establecer esta clausura.

\section{La democracia como bien jurídico protegido}

A bien de analizar la semántica a partir de la cual la Ley de Defensa de la Democracia construyó el nuevo bien jurídico que buscaba tutelar, es necesario advertir en un cambio terminológico que el proyecto del Ejecutivo introducía en el Código Penal. En su artículo 1 modificaba el acápite del capítulo I del título $\mathrm{X}$ del libro II del Código Penal, reemplazando la expresión «rebelión» por la de «atentados al orden constitucional y la vida democrática» ${ }^{[17]}$. En el mensaje que acompañó el proyecto, el Ejecutivo justificaba este cambio aludiendo a que este tenía el «fin de privar a esta aberrante conducta la connotación heroica y romántica que posee el término rebelión». Son dos las cuestiones que nos interesa resaltar en este sentido. Un primer aspecto es que este cambio registra un cambio de valoración respecto al paradigma del derecho revolucionario que es coherente tanto con la crítica generalizada a la violencia política, así como con esta clausura de lo político antes mencionada ${ }^{[18]}$. El otro es que el nuevo término ponía en relación «constitución»y «democracia» de una manera novedosa para el discurso constitucional argentino.

Como afirma Baigún (1995), los legisladores no se explayaron demasiado en especificar la semántica usada para dar forma al nuevo bien jurídico protegido. Sin embargo, las pocas explicaciones que se registraron nos permiten echar luz sobre la matriz jurídica desde la cual fue enunciada la Ley de Defensa de la Democracia. En la presentación del proyecto remitido por la Cámara de Diputados, el miembro informante por la mayoría en el Senado, Fernando de la Rúa (UCR), aportó algunos elementos para justificar la terminología empleada aludiendo al «concepto más amplio de democracia constitucional, recogido y perfeccionado por la doctrina contemporánea ${ }^{[19]}$. En efecto, si bien el de «democracia constitucional» es un concepto de amplio arraigo en la filosofía política y en la doctrina jurídica, es cierto que durante la segunda mitad del siglo $\mathrm{XX}$ y al fragor de las experiencias del fascismo y el nazismo en Europa y de las dictaduras militares en el Cono Sur, el término se cargó de un sentido histórico particular al tiempo que su uso se expandió a nivel global a tal punto de ser identificado como la única forma política legítima (ver: Nino, 1996; Rosanvallon, $2006)^{[20]}$.

En su alocución, de la Rúa proyectaba en el concepto de «democracia constitucional» la tentativa de una síntesis de las dos grandes tradiciones jurídicas argentinas. Desde su perspectiva, son dos los estratos jurídicos que convergen en dicho concepto. Mientras que el primero de ellos refiere a la matriz liberal-republicana fundacional propia del siglo XIX, el segundo obedecería a matriz del constitucionalismo social más vinculada a la realización efectiva de la soberanía popular a través del reaseguro de las condiciones de participación de los grupos sociales en la vida pública. Para de la Rúa, estos dos estratos 
se debían amalgamar en torno a una definición en la cual «el gobierno del pueblo y para el pueblo conforma un régimen político limitado por la forma republicana y representativa» ${ }^{[21]}$. El potencial igualador de la democracia y su freno contra-mayoritario quedarían así mutuamente referidos en una misma unidad de sentido. De tal manera que, para el senador de la Capital Federal:

«Son dos vertientes históricas que convergen en una síntesis fecunda: por un lago, el largo esfuerzo de su organización política para asegurar el orden jurídico y los beneficios de la libertad a los criollos y a todos los hombres del mundo; por el otro, el progreso espectacular de la igualdad y la justicia social, el sostenido proceso por garantizar la soberanía popular, los derechos de los trabajadores, la participación de todo el pueblo en la cosa pública. Constitución y democracia confirman una sustancial unidad» ${ }^{[22]}$.

Esta interpretación que ofrece De la Rúa va en sintonía con la fórmula «república democrática» empleada con regularidad por Alfonsín, sobre todo luego de que, en 1985 con la creación del Consejo para la Consolidación de la Democracia (CCD), se empezaran a delinear los ejes de una reforma constitucional (ver: Alfonsín, 1996). En efecto, el 15 de abril de 1985 en ocasión de la presentación de proyecto de ley preparado por el CCD que buscaba trasladar la Capital Federal a Viedma, Alfonsín identificaba a la transición iniciada en 1983 como un momento de ruptura histórica y planteó que el cambio constitucional propuesto implicaría «la fundación, en la práctica, de una Segunda República» y advertía que: «la que fue fundada en el siglo pasado respondió a un modelo que debe ser superado y enfrentó dramáticos problemas políticos e institucionales que se agravaron en las últimas décadas» ${ }^{[23]}$. Para el presidente radical, esta segunda república no podía ser sino una «república democrática»; formulación que debía permitir superar la antinomia entre el constitucionalismo liberal-republicano del siglo XIX y las exigencias del protagonismo popular del siglo XX. La lectura histórica de la cual partía el presidente radical era que durante el largo ciclo de inestabilidad en Argentina, estas dos tradiciones se enfrentaron sin lograr nunca una fórmula de mutuo compromiso. De ahí que, como afirma Aboy Carlés (2010), en la idea de una «segunda república» se articularan tanto una crítica a la dicotomización del espacio político propia del ciclo de inestabilidad iniciado en 1930, como la promesa de su superación.

Bajo este marco de enunciación, el bien jurídico protegido que introdujo la Ley de Defensa de la Democracia se compone de dos términos: el orden constitucional y la vida democrática. Si bien el primero no resulta ajeno al discurso jurídico, la fórmula «vida democrática» es bastante particular. La incorporación de la voz «vida» le da a la vez un sentido dinámico y de desenvolvimiento que contrasta con la connotación más rígida de «orden constitucional», al mismo tiempo que lo carga de una semántica en la cual lo que se busca proteger es, ni más ni menos, que una vida ${ }^{[24]}$. Esto parece confirmarse cuando en distintas intervenciones, al referirse a la democracia los legisladores afirmaban que su valía excedía a la de una simple forma de gobierno, y que se trata de una «forma de vida» que la misma historia se había encargado de ratificar como consustancial al ser nacional.

En la justificación de la decisión de hacer de la democracia un bien tutelado, la relación entre ley y juicio histórico emerge como una figura retórica fundamental. Desde este punto de vista, la función de la ley era la de formalizar por vía del 
derecho lo que era una decisión colectiva sobre el orden legítimo que la propia experiencia histórica se había encargado de validar. La experiencia histórica era tomada al mismo tiempo como experiencia jurídica. En este sentido, para Balbino Pedro Zubiri (UCR) el agravante incorporado al 226 del Código Penal para el caso en que la acción esté destinada a alterar de modo permanente el sistema democrático estaba justificado pues en este caso, se trata de «trastocar un modelo de sociedad que fue ratificado por diferentes generaciones de nuestro pueblo, cada vez que tuvieron la oportunidad de pronunciarse ${ }^{[25]}$. Este motivo retórico que caracteriza a la democracia como una conquista del pueblo se repite en varias intervenciones. Para De la Rúa, la democracia era «el ideal histórico de nuestra Nación»; mientras que para Luis Agustín Brasesco (UCR) el proyecto era la «expresión política de una aspiración concreta de un pueblo frustrado mil veces, que mil veces se ha levantado sobre las ruinas» ${ }^{[26]}$. Así también para el senador formoseño Manuel Vidal (MID), «la democracia, en cuanto gobierno del pueblo, es una conquista arrancada a las oligarquías dueñas del poder económico» ${ }^{[27]}$. Sin embargo, la ley no sólo formalizaba lo que ya los hechos habían demostrado, sino que también actuaba como un manifiesto, una declaración que reforzaba esta vinculación histórica de la nación argentina con la democracia. Para el diputado Alfredo Mosso (UCR), la iniciativa tenía «una profunda importancia ética y política porque tiende a terminar el tutelaje político en la Argentina». De ahí que el senador Adolfo Gass (UCR), solicitara que «esta ley se publicitara en la medida necesaria, que se enviaran folletos impresos en el Congreso a todas las escuelas del país y a todos los cuarteles» ${ }^{[28]}$.

Bajo estos preceptos la Ley de Defensa de la Democracia agregaba un nuevo párrafo al artículo 226 del Código Penal y que hasta ese momento había reglamentado el delito de rebelión. A la figura básica de este artículo que imponía penas sobre quienes se alzaren en armas en contra de la constitución y los poderes públicos emanados de ella, se le agregan dos nuevos agravantes. El primero refería al caso que estas acciones tuvieran como fin «cambiar de modo permanente el sistema democrático de gobierno» ${ }^{[29]}$. Y un segundo aspecto que tenía que ver con la calidad del agente, en la medida en que este acto «fuese perpetrado por personas que tuvieren estado, empleo o asimilación militar» ${ }^{[30]}$.

Estos cambios fueron recibidos escépticamente por legisladores de diversos partidos. Para el senador justicialista por La Rioja, Carlos Menem, el delito de rebelión había sido siempre una cuestión difícil de elaborar desde el derecho penal, pues si bien «se lo incluye en los delitos políticos», lo cierto es que «se ha llegado a negar el tratamiento de este delito como tal» ${ }^{[31]}$. En efecto, el punto en cuestión al que alude Menem es el difícil discernimiento entre lo político como régimen de excepcionalidad y lo jurídico al que refería Dotti (2011). El senador recordaba que «cuando triunfa la rebelión, la sanción de este delito nunca se aplica; por ello, se ha dicho que también éste es el delito de los vencidos o derrotados y no para los triunfadores $\gg$. Desde la perspectiva del riojano, fuera de su carácter expresivo, las modificaciones que introducía ley de Defensa a la Democracia resultaban jurídicamente inefectivas.

En un sentido similar, para Ricardo Leconte (PLCo) la nueva formulación del 226 del Código Penal establecía «delitos que se tipifican con la revolución triunfante o el gobierno de facto triunfante»; por lo que «si las autoridades 
son destituidas y ejerce el poder un gobierno de facto, estas normas carecen de trascendencia». Bajo este argumento, el establecimiento de la no prescripción de los delitos que introducía la propuesta de ley podía incluso resultar pernicioso en el caso que se tenga que discutir una eventual salida de un gobierno de facto; pues «al saber que le cabe una sanción incuestionable en el futuro demorará la fecha de entrega del poder, de tal manera que esta norma es de dudosa aplicación y sus efectos pueden no tener el beneficio pensado por el legislador» ${ }^{[32]}$.

Fueron diversas las réplicas a los argumentos de Leconte y Menem. En relación con la interrupción de la prescripción durante el tiempo en el cual el orden constitucional se encontrara interrumpido, el senador justicialista por Tucumán Ramón Adrián Araujo advirtió que el objetivo era «no dejar en la impunidad a los autores de los atentados contra el orden». Por su parte, el senador radical Antonio Tomás Berhongaray le restaba validez al argumento del riojano al afirmar que éste

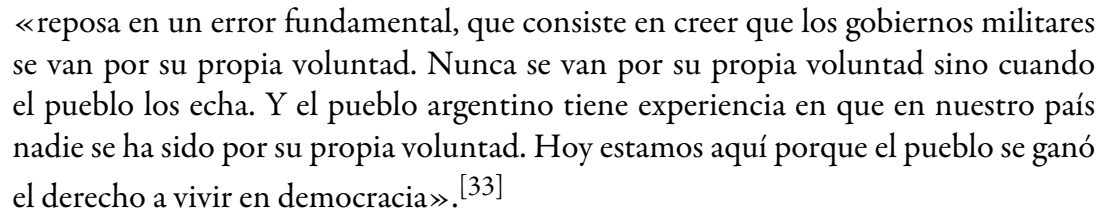

Reiterando con ello la concepción que veía en la democracia un destino inevitable para la Argentina y una conquista histórica que debía quedar a resguardo mediante la aprobación de la ley.

Vemos entonces que en la forma en la cual la Ley de Defensa de la Democracia construye a la democracia como bien jurídico resulta fundamental la clausura de lo político, si se entiende esto como una disputa por la forma política. En efecto, al convertirse en un bien a resguardo del derecho, la democracia aparece como una magnitud jurídica cuasi natural. Sin ser explícito, esta forma de argumentación recuerda a la retórica iusnaturalista tendiente a fundamentar la ley en la existencia de ciertos derechos universales de carácter previo a su positivización estatal ${ }^{[34]}$. Dentro de este marco, la experiencia histórica actúa como una especie de validación de esta decisión sobre el orden colectivo, en la cual el fracaso de todo gobierno de fuerza es tomado como un dato inevitable. La democracia queda así elevada al carácter de un destino. En todo caso, dentro de esta argumentación la ley recupera y relanza lo que en realidad es una «lección de la historia».

Sin embargo, este ensayo de clausura de lo político se encuentra en el propio proyecto del Ejecutivo algunas tensiones internas. En efecto y como veremos a continuación, la propuesta de legislar sobre un derecho de resistencia que faculte a los ciudadanos a tomar las armas para defender el bien jurídico protegido fue percibido por distintos legisladores como un potencial peligro y una concesión al uso de la violencia como medio de participación política.

\section{IV.El derecho de resistencia en la Ley de Defensa de la Democracia}

Uno de los aspectos que mayor controversia generó en la discusión sobre la Ley de Defensa de la Democracia fue la propuesta de incorporar un nuevo inciso en el artículo 34 del Código Penal. A este artículo que regula las condiciones en 
las que una conducta no es punible, el proyecto de ley agregaba un nuevo inciso que consideraba como inimputable a aquel que «causare un mal como medio necesario, razonable e idóneo para resistir la implantación o el mantenimiento de un poder público ajeno a los previstos en la Constitución Nacional, o alguna de sus medidas». De esta manera el objetivo del Ejecutivo era legislar sobre el derecho de resistencia. En efecto, se trataba de una variante del derecho a la legítima defensa que, en palabras de Zubiri (UCR), consistía en «darle categoría legislativa al derecho de resistencia a la opresión, no penando a quien - por ejemplo- empuña las armas para defender la Constitución». De esta manera, «ante un gobierno que se coloca al margen de la Constitución, el pueblo se aparta también de las normas constitucionales que reglan la sucesión gubernamental y empleando la fuerza derroca a quienes dirigían el Estado de manera tiránica» ${ }^{[35]}$. Para el legislador radical por Buenos Aires se trataba de «un derecho natural y subjetivo» susceptible de ser incorporado al Código Penal. Vemos entonces que el axioma schmittiano seguido por Dotti queda aquí invertido: el régimen de excepcionalidad no corresponde al Estado sino a los ciudadanos. La prerrogativa de apartarse de la constitución para defenderla se habilita cuando la unidad sustancial entre democracia y constitución es violentada por la conquista por la fuerza del aparato coactivo del Estado.

Sin embargo, para el diputado Ricardo Ramón Balestra del Partido Liberal de Corrientes, esta incorporación constituía un peligro ya que «el derecho de resistencia a la opresión ha sido invocado en términos constitucionales tanto para justificar el mantenimiento de los poderes constituidos como para intentar explicar el alzamiento contra ellos». Para desestimar la juridicidad de este derecho, Balestra aludió a los constitucionalistas Sánchez Viamonte y a Sebastián Soler, valiéndose de ellos para afirmar «que no se trata de un derecho»y que se «ha considerado inadmisibles jurídicamente sus consecuencias lógicas». Bajo este último registro, señala la imposibilidad de que «cada argentino pueda constituirse individualmente en el árbitro del orden constitucional, lo cual precisamente está prohibido por el artículo 22 de la misma Constitución». Siguiendo esta argumentación, Balestra señaló la imposibilidad de que los jueces puedan establecer un criterio homogéneo respecto a cuándo puede ser aplicado este derecho, creando así «situaciones que podrían prestarse a muy disímiles interpretaciones por parte del juzgador frente a casos concretos» ${ }^{[36]}$.

La propuesta del diputado Balestra concerniente ya sea a eliminar este artículo o modificar su redacción para hacer más restrictiva su interpretación fue rechazada por la Cámara de Diputados. Sin embargo, el dictamen de la mayoría en el Senado coincidió con la apreciación del diputado correntino y decidió eliminarlo. En su informe de Comisión, De la Rúa advirtió que la incorporación propuesta por el Ejecutivo y validada en Diputados se trataba de «una norma de difícil interpretación, que alguien pudiera querer invocar no para justificar la defensa de la Constitución, sino por la violencia misma bajo el pretexto de otra motivación política». En un marco justificatorio en el cual se intentaba clausurar un pasado caracterizado por la violencia política, la adición al artículo 34 del Código Penal introducía una tensión difícil de resolver. En este sentido, De la Rúa cerraba la cuestión afirmando que «estamos en contra de toda forma de terrorismo» y fundamentaba la decisión de eliminar esta cláusula en el propio espíritu de la ley de Defensa de la Democracia: 
«Y como dictamos esta ley para la defensa de la paz y la vigencia del orden legal, hemos querido despejar toda duda y no hemos incluido ese inciso, considerando suficientes las demás normas que integran el articulado, para la defensa del orden constitucional y de la vida democrática» ${ }^{[37]}$.

En la Convención Constituyente de 1994, sin embargo, este derecho de resistencia fue retomado y plasmado en el artículo 36, tomando como antecedente el espíritu del proyecto original de Ley de Defensa de la Democracia. Es interesante advertir la actualidad que ganó el derecho de resistencia en el discurso constitucional de la segunda mitad del siglo XX. En efecto, este reemerge como derecho positivo durante este periodo y es incorporado a diversas Constituciones post-transicionales a lo largo del globo. Cláusulas parecidas a la que intentó legislar la ley de Defensa de la Democracia fueron agregadas a las constituciones de Alemania (1949), Portugal (1976) y Grecia (1975). También es posible encontrar una referencia a este derecho en el propio preámbulo de la Declaración Universal de los Derechos Humanos (1948) en la medida que se considera «esencial que los derechos humanos sean protegidos por un régimen de Derecho, a fin de que el hombre no se vea compelido al supremo recurso de la rebelión contra la tiranía y la opresión».

\section{Conclusiones: ¿̨la democracia como derecho pre-estatal?}

El análisis de los debates parlamentarios de la Ley de Defensa de la Democracia nos ha permitido indagar tanto en los sentidos y representaciones que le dieron forma a esta ley, así como en la retórica jurídica que se empleó para convertir a la democracia en un bien jurídico protegido. A partir de nuestro marco de análisis en torno a una fenomenología del legislador, hemos destacado el estrecho vínculo que se plantea entre la promulgación de las leyes y la experiencia histórica. En este sentido se advierte que la apelación a la historia no sólo es parte sustancial del discurso justificatorio de la Ley de Defensa, sino que se mira propio al derecho como una forma de intervención en la historia. Desde esta perspectiva, el legislador se considera a sí mismo como un actor de la historia (en el sentido de que la representa y la actúa) y el derecho es percibido como un instrumento ya sea para formalizar un hecho develado por ella (el valor de la democracia como única forma de organización posible), para intervenir en una tendencia (poner fin al tutelaje político) o para expresar un deseo colectivo (no repetir el pasado).

Si bien no hay que sobreestimar la impronta de esta norma en el fin del largo ciclo en el que alternaron gobiernos de facto y de iure, si nos permiten echar luz sobre la tentativa de clausurar todo espacio político por fuera de la relación interna que se establece entre Constitución y democracia. Luego de 1983 la democracia y su orden jurídico delimitan como la única superficie de inscripción de la política. En la construcción de esta frontera el derecho resulta una herramienta central.

Esta relación que hemos identificado entre la ley y la experiencia histórica ofrece un filón interesante para retomar la aporía a la que arribó el análisis de Dotti reseñado en la introducción. Como hemos afirmado, en la construcción de la democracia como bien jurídico protegido opera una diferenciación entre lo jurídico y lo estatal cuyo orden de prelación resulta extraña al marco decisionista schmittiano. Desde la retórica mediante la cual es enunciada la ley analizada, 
lo que devela la experiencia histórica es el valor de la democracia como forma de vida cualificada. De tal manera que ésta es situada al mismo nivel que los derechos inalienables del ser humano. De ahí que, tal como aparece en el artículo 36 constitucional, se pueda oponer la defensa de la democracia y su orden constitucional a la propia capacidad del Estado de hacer valer y respaldar el derecho positivo. Desde este punto de vista estas dos cuestiones no se encontrarían jurídicamente en el mismo nivel. Se trataría, en efecto, de dos derechos de naturaleza diferente. La democracia es presentada entonces como una precondición del orden estatal en tanto aparece referido a un sujeto político que excede al Estado. Situación que, si bien es a todas luces falsa como dato histórico, nos habla de una re-jerarquización de los términos producto de los importantes cambios en el discurso jurídico que se observan durante la segunda mitad del siglo XX. En este sentido, la lógica que sigue la Ley de Defensa no debe verse como un caso aislado, sino como parte de un proceso global en la cual la manera en que se relacionan derecho y democracia adquiere nuevos matices.

En efecto, con las experiencias de los regímenes totalitarios surgidos en Europa como trasfondo inmediato, la Declaración Universal de los Derechos Humanos significó un profundo desafío para la filosofía del derecho. Sin que exista actualmente un consenso sobre la justificación jurídica de esta batería de derechos, la cuestión reviste una gran importancia. Su progresiva ratificación a través del reconocimiento constitucional de los diferentes pactos internacionales les ha conferido una efectividad práctica que trasciende su mero papel declarativo. Así, por ejemplo, en el artículo 21 de la Declaración Universal se afirma que «toda persona tiene derecho a participar en el gobierno de su país, directamente o por medio de representantes libremente escogidos $\gg . ¿ C u a ́ l$ es la fundamentación jurídica de este derecho inalienablemente a la democracia? ¿Cómo conciliar el derecho a la auto-derminación de los pueblos con la afirmación de una sola forma de organización política universalmente válida?

Una de las posturas que intentaron resolver estos enigmas fue emprender una «vuelta al derecho natural». En efecto, como afirma Guiddo Fasso «después de la experiencia de los regímenes totalitarios fascistas y enfrentados a la amenaza de otros regímenes totalitarios, muchos piensan que una defensa de la democracia no puede ser asegurada excepto a través de la afirmación de valores jurídicos universales y absolutos, valores que la legislación del Estado nunca puede contradecir» (Fassó, 1962: 97). Sin embargo, Fassó se pregunta si la fragilidad democrática en Europa y América Latina se debió a que «la legislación de estos países ignoró valores absolutos o porque se adhirieron demasiado a algunos de ellos» (Fassó, 1962: 97). En su polémica con Robert L. Calhoun, el jurista italiano advierte que históricamente el derecho natural ha servido tanto para afirmar la libertad como para negarla. La respuesta que ofrece Fassó lo sitúa en una vía alterna a la falsa disyuntiva entre el positivismo estatalista y el derecho natural. Consideramos su posición relevante para nuestro abordaje en la medida en que enfatiza el papel de la experiencia histórica.

Para Fassó, la vuelta al derecho natural disimula un rasgo fundamental que no debe pasar desapercibido: la necesidad de que el derecho emanado por el Estado sea evaluado a partir de un criterio de justicia superior (a la vez jurídico y extraestatal). Sin embargo, niega que la referencia a un corpus doctrinal inmutable y transhistórico sirva para esto. Por el contrario, estos criterios siempre son 
contingentes y forman parte de un proceso de descubrimiento por parte de la sociedad que los autoriza y/o los rechaza. De tal manera que para que este criterio supra-estatal «se convierta en la base de una vida verdaderamente democrática $\mathrm{y}$, por lo tanto, moralmente democrática incluso antes de ser jurídicamente democrática, debe estar viviendo, concreta y realmente en la conciencia histórica de los hombres (...) Para ser la base de la democracia, el criterio de valoración del derecho positivo debe, en suma, ser histórico» (Fassó, 1962: 107). Para Fassó, la experiencia histórica actúa como principio de inteligibilidad de este criterio valorativo y propone que este debe ser entendido como «el sistema normativo que emerge de la valoración de los miembros de la sociedad».

Volviendo a la discusión con Dotti, podemos afirmar que la retórica bajo la cual está construida la democracia como un bien jurídico protegido, indica la constitución de un sujeto político que no coincide uno a uno con la capacidad del Estado para decidir sobre el estado de excepción. En esta línea nos resulta sugerente la postura de Grossi (2014) sobre la Constitución italiana postfacista a la que califica de posmoderna ${ }^{[38]}$. Si el discurso jurídico que prevaleció durante el siglo XIX condenaba a la sociedad y a su dinámica plural y conflictiva a la irrelevancia jurídica, aquel que empieza a surgir en el siglo XX postula al propio espacio de lo social como sujeto político instituyente. No se trata ya del pueblo como principio formal y abstracto del constitucionalismo decimonónico, sino de la sociedad policlasista que se auto-organiza a través del principio de soberanía popular.

En este sentido el «derecho a la democracia» al que hemos hecho referencia debe ser considerado como el índice de la emergencia de un sistema normativo que pertenece a la sociedad y que el Estado está obligado a mantener a resguardo. Bajo esta lógica, la legitimidad del Estado tiene como punto de partida la ratificación de este nuevo sujeto instituyente: la sociedad democrática ${ }^{[39]}$. Si bien es necesario profundizar desde una perspectiva global e interconectada en los cambios en el discurso jurídico que trajeron consigo las transiciones a la democracia, la revisión de los debates parlamentarios en torno Ley de defensa a la democracia nos ha permitido indagar en las singularidades que adquirió este proceso en el caso argentino.

\section{Referencias}

AZZOLINI, Nicolás (2018). «Los límites de la democracia argentina. Lecturas desde el proyecto de ley de defensa de la democracia de 1961», en: Estudios Sociales, 54, Santa Fe, Argentina, Universidad Nacional del Litoral, pp. 119-142.

ABOY CARLÉS, Gerardo (2001). Las dos fronteras de la democracia argentina: la reformulación de las identidades politicas de Alfonsin a Menem. Rosario, Homo Sapiens Ediciones.

ABOY CARLÉS, Gerardo (2010). «Raúl Alfonsín y la fundación de la segunda república», en GARGARELLA et al., Discutir Alfonsín. Buenos Aires, Siglo XXI.

ACUÑA, Carlos; GONZÁLEZ BOMBAL, María Inés; JELIN, Elizabeth; LANDI, Oscar; QUEVEDO, Luis Alberto; SMULOVITZ, Catalina; VACCHIERI, Ariana. (1995). Juicios, castigos y memorias. Derechos humanos y justicia en la politica argentina. Buenos Aires: Nueva Visión. 
ALFONSÍN, Raúl (1996). Democracia y consenso: a propósito de la reforma constitucional. Buenos Aires: Corregidor.

BAIGÚN, David (1995). «El delito de atentado al orden constitucional y la vida democrática y la reforma de la constitución nacional», en Estudios sobre la Reforma Constitucional de 1994. Buenos Aires, Depalma.

COSSIO, Carlos (2002). El Derecho en el Derecho judicial, El Foro, Buenos Aires.

CRENZEL, Emilio. (2008). La historia política de Nunca Más. Buenos Aires: Siglo XXI.

DÍAZ, Elías (1966). Estado de derecho y sociedad democrática. Cuadernos para el diálogo, Madrid.

DOTTI (2011). «La cuadratura del círculo: la Constitución argentina como testimonio de la imposible normativización de lo político» en Las vetas del texto, Buenos Aires, Las cuarenta, pp. 16-245.

FASSÒ, Guido (1962). «On Natural Law as the Basis of Democracy Note», en Natural Law Forum, Paper $N^{\circ} 74$, Notre Dame Law School.

FERRARI, Marcela (2017). «La Democracia Cristiana argentina durante la dictadura cívico-militar y la transición temprana» (1976-1985), en Historia, 50, vol. I, enero-junio 2017, pp. 49-77.

FELD, Claudia (2002). Del estrado a la pantalla: las imágenes del juicio a los ex comandantes en Argentina. Siglo XXI de España Editores.

FRANCO, Marina (2012). Un enemigo para la nación: orden interno, violencia y «subversión», 1973-1976. Fondo de Cultura Económica, Argentina.

GALANTE, Diego (2015). «Los debates parlamentarios de <Punto Final> y $<$ Obediencia Debida>: el Juicio a las Juntas en el discurso político de la transición tardía», en Clepsidra. Revista Interdisciplinaria de Estudios sobre Memoria, vol. 2, 4, p. 12-33.

GALLI, Carlo (2018). Genealogía de la politica. Carl Schmitt y la crisis del pensamiento politico moderno. UNIPE, Argentina.

GONZÁLEZ BOMBAL, Inés (1995). «Nunca Más: el Juicio más allá de los estrados», en ACUÑA, Carlos; GONZÁLEZ BOMBAL, María Inés; JELIN, Elizabeth; LANDI Oscar; QUEVEDO, Luis Alberto; SMULOVITZ, Catalina; VACCHIERI, Ariana. (1995), Juicios, castigos y memorias. Derechos humanos y justicia en la política argentina. Buenos Aires, Nueva Visión

GROSSI, Paolo (2014). «La Constitución Italiana como expresión de un tiempo jurídico posmoderno» en Historia constitucional: Revista Electrónica de Historia Constitucional, 15, pp. 205-237.

JELIN, Elizabeth (2007). «Public memorialization in perspective: Truth, justice and memory of past repression in the Southern Cone of South America», en The International Journal of Transitional Justice, vol. 1, 1, p. 138-156.

MALAMUD, Goti, J. (2000). Terror y justicia en la Argentina. Buenos Aires, Ediciones de la Flor.

NINO, Carlos S. (1996). Juicio al mal absoluto. Argentina, Siglo XXI.

PIOTTI, Daniel; FERNANDEZ, Alberto (1985). Defensa de la democracia. Buenos Aires, Tarso.

RICHIR, Marc (2013). La contingencia del déspota. Brumaria, España.

ROSANVALLON, Pierre (2006). La democracia inconclusa. Historia de la soberania del pueblo en Francia. Colombia, Universidad Externado. 
VELÁZQUEZ RAMÍREZ, Adrián (en prensa). «La relación entre democracia y derecho durante la transición argentina», en Perfiles Latinoamericanos, Facultad Latinoamericana de Ciencias Sociales, México

VERDÚ, Pablo Lucas (1981). «Constitución española de 1978 y sociedad democrática avanzada», en Revista de derecho político, 10, pp. 7-46.

VEZZETTI, Hugo (2008). «El testimonio en la formación de la memoria social», en VALLINA, Cecilia (org.) Critica del testimonio. Ensayos sobre las relaciones entre memoria y relato. Beatriz Viterbo Editora, Buenos Aires.

YANZÓN, Rodolfo (2011). «Los juicios desde el fin de la dictadura hasta hoy», en, ADREOZZI, G. (coord.) Juicios por Crimenes de lesa humanidad en Argentina. Ed. Atuel, Buenos Aires.

\section{Referencias}

VELÁZQUEZ RAMÍREZ, Adrián (2020), "La relación entre democracia y derecho en el inicio de la transición argentina: la anulación de la autoamnistía militar", Perfiles latinoamericanos, 28, Vol. 56, pp. 1-26.

\section{Notas}

[1] En efecto, para Schmitt todo orden jurídico se funda en una decisión política que le antecede. En este sentido, la perspectiva decisionista desarrollada por el jurista alemán (1922 y 1928) se caracteriza por subordinar lo jurídico a lo político (interpretado exclusivamente como la capacidad de decidir sobre el estado de excepción). Dentro de este esquema el Estado se reserva la posibilidad de suspender el orden jurídico para resguardar la unidad estatal frente amenazas internas y externas. Para este tema remitimos al monumental estudio de Galli (2018), recientemente publicado al español.

[2] Estas leyes fueron: 1) derogación de la Ley 22929; 2) Ley de Protección del Orden Constitucional y de la Vida Democrática; 3) modificación del Código Penal en materia de torturas; 4) modificación del Código de Procedimientos en Materia Penal, sobre recursos contra sentencias de tribunales militares; 5) modificación del Código de Procedimientos en Materia Penal sobre excarcelación; 6) modificación del Código de Justicia Militar y otras cuestiones conexas; 7) aprobación del Régimen Provisorio de Normalización de las universidades nacionales.

[3] Para una reflexión más amplia sobre el papel de la práctica representativa durante la transición, ver: Velázquez (2020).

[4] El abordaje fenomenológico fue parte central de la contribución del jurista argentino Carlos Cossío al debate sobre la interpretación de la ley. Desde su perspectiva, el legislador en su experiencia respecto a la creación de una ley tendría en cuenta a) la estructura constitucional dada, b) los contenidos dogmáticos volcados en la ley y, c) la valoración jurídica de la ley respecto a los valores jurídicos que le son inmanentes. La otra gran referencia para precisar esta dimensión es la obra de Richir (2013) y sus planteamientos en torno a una «fenomenología de lo político», la cual parte de reconocer una dimensión excedente y trascendente de lo político respecto a sus realizaciones siempre parciales en la política. En el caso que nos interesa, esta excedencia se evidencia en cómo la ficción de la voluntad general constituye la gran escena teatral que actúa como supuesto en el «decir la ley» del legislador. Esta dimensión fenomenológica de lo político nos parece sumamente relevante en el marco de la historia conceptual para pensar el registro performativo/experiencial de los conceptos políticos fundamentales. La especificación de esta perspectiva será objeto de un trabajo posterior.

[5] Fueron derogados los artículos 1, 2, 3, 4, 5, 10, 11 y 12 de la Ley 20840 (Ley de Seguridad Nacional), y las leyes de facto números 21259 (expulsión de extranjeros), 21264, 21267, 21268, 21272, 21322, 21325, 21449; los artículos 1, 2, 3 y 7 de la Ley 21459; 21460 (Procedimientos 
e investigación contra la subversión), 21461 (Consejos de guerra), 21463 (Reforma del Código de Justicia Militar), 21634, 21886, 22928 (Ley de enjuiciamiento de actividades terroristas y subversivas) y 21338 (Reforma del Código Penal). Ante la complejidad de la tarea, el senador Leconte acusó ciertos descuidos en la técnica legislativa empleada en Diputados al advertir que las leyes 21267 y 21463 ya habían sido derogadas por la Ley 22928, el 29 de septiembre de 1983. Por situaciones como esta hubo opiniones de lo que debía proceder es una reforma integral del Código Penal.

[6] Diario de sesiones de la Cámara de Diputados, 16/12/1983, p. 117.

[7] Para un estudio sobre cómo se construyó este límite en otras leyes represivas, remito al trabajo de Azzolini (2018), mismo que ofreció interesantes claves para pensar esta tensión en la ley que trabajamos.

[8] Diario de Sesiones del Senado, 30/05/1984, p. 500.

[9] Para una reconstrucción de la Democracia Cristiana en la década de los ochentas, ver Ferrari (2017).

[10] Diario de Sesiones de la Cámara de Diputados, 2 y 3/02/1984, p. 1119.

[11] Diario de Sesiones de la Cámara de Diputados, 16/12/1983, p. 117.

[12] Diario de Sesiones de la Cámara de Diputados, 16/12/1983, p. 118

[13] Diario de Sesiones del Senado, 30/05/1984, p. 502.

[14] Leconte fue intendente de facto de la ciudad de Corrientes en el periodo 1982-1983.

[15] Diario de Sesiones del Senado, 30/ 05/1984, p. 502.

[16] Diario de Sesiones de la Cámara de Diputados, 16/12/1983, p. 118.

[17] En el proyecto finalmente aprobado, esta cuestión pasó al artículo 5. En la revisión hecha por el Senado del proyecto aprobado en Diputados, se decidió eliminar la fórmula vida «democrática», dejando sólo «atentados contra el orden constitucional». Sin embargo, cuando volvió a Diputados se volvió a afirmar que la fórmula compuesta por los dos elementos (orden constitucional y vida democrática) era la que mejor captaba la totalidad del bien jurídico protegido.

[18] En el senado, Balbino Pedro Zubiri (UCR), ensayó un rescate del concepto de revolución, diferenciándolo de los golpes de Estado.

[19] Diario de Sesiones de la Cámara de Diputados, 2 y 3 de febrero de diciembre de 1984, p. 498.

[20] Según DataWorld, en 1945 existían 12 democracias constitucionales y 137 regímenes autocráticos. A partir de este año esta relación se fue modificando progresivamente a favor de las democracias constitucionales. Para 1989 existían 105 autocracias contra 51 democracias y para el 2002 por primera vez el número de democracias superó al de autocracias (92 vs. 84). Si bien este tipo de ejercicios estadísticos siempre puede ser discutible el concepto normativo del que parte, consideramos que si alcanza a reflejar la expansión de la fórmula «democracia constitucional» a nivel global.

[21] Diario de Sesiones de la Cámara de Senadores, 30/05/1984, p. 498.

[22] Diario de Sesiones de la Cámara de Senadores, 30/05/1984, p. 498.

[23] La Nación, 16 de abril de 1986

[24] Esta concepción remite a la diferencia entre Bios y Zoe.

[25] Diario de Sesiones de la Cámara de Diputados, 2 y 3/02/1984, p. 498.

[26] Diario de Sesiones del Senado, 30/05/1984, p. 523. 
[27] Diario de Sesiones del Senado, 30/05/1984, p. 516.

[28] Diario de Sesiones del Senado, 30/05/1984, p. 524

[29] Se debe advertir que el concepto de «democracia» incorporado aquí no aparece en la primera sección de la Constitución cuando define la forma de gobierno de la Nación como «representativa, republicana y federal».

[30] Otro aspecto que propició la discusión de la Ley de Defensa de la Democracia fue la revisión del entramado civil de los golpes de Estado. En efecto, el proyecto de ley tipificaba como delito el «colaboracionismo» tanto de civiles como de funcionarios de cualquiera de los tres poderes del Estado en un eventual gobierno de facto. De esta manera, se imponían penas a los «miembros de cualquiera de los tres poderes del Estado nacional o provincial que, luego de modificada por la fuerza Constitución Nacional o depuesto algún de los poderes públicos, continuaran en sus funciones» así como quienes «asumieren estas funciones».

[31] Diario de Sesiones del Senado, 30/05/1984, p. 509.

[32] Diario de Sesiones del Senado, 30/05/1984, p. 502.

[33] Diario de Sesiones del Senado, 30/05/1984, p. 521.

[34] Este tema es retomado en las conclusiones.

[35] Diario de Sesiones de la Cámara de Diputados, 2 y 3/02/1984, p. 1135.

[36] Diario de Sesiones de la Cámara de Diputados, 2 y 3/02/1984, p. 1136

[37] Diario de Sesiones del Senado, 30/05/1984, p. 497.

[38] Bajo esta hipótesis, Grossi define el sentido de la Constitución en el siglo XX en términos que permiten establecer un diálogo con la postura de Fassó: «De hecho, si la Constitución de la modernidad aparece como 'carta de derechos', la <Constitución> del novecientos es, antes que nada, un hito histórico y, por ello, un auténtico patrimonio de idealidad y de experiencias. Es, en efecto, el signo de identidad de una comunidad en el momento de madurez de su autoconciencia» (Grossi, 2014: 206)

[39] Así, por ejemplo, en el proceso que desemboca en la Constitución española de 1978, el concepto de «sociedad democrática» adquiere el valor de un principio articulador central. Ver: Díaz (1966) y Verdú (1981). 